OPEN ACCESS

Edited by:

Philippe Guilpain,

Université de Montpellier, France

Reviewed by:

Fernando Cardona

Consejo Superior de Investigaciones

Cientificas (CSIC), Spain

Audrey Sabbagh,

Université Paris Descartes, France

*Correspondence:

Nathalie C. Lambert

nathalie.lambert@inserm.fr

these authors have contributed equally to this work.

Specialty section: This article was submitted to Immunological Tolerance and Regulation,

a section of the journal

Frontiers in Immunology

Received: 26 April 2018

Accepted: 09 July 2018

Published: 14 August 2018

Citation:

Di Cristofaro J, Karlmark KR, Kanaan SB, Azzouz DF, El Haddad M, Hubert L, Farge-Bancel D, Granel B, Harlé JR, Hachulla E, Pardoux E, Roudier J, Picard C and Lambert NC (2018) Soluble HLA-G Expression Inversely Correlates With Fetal

Microchimerism Levels in Peripheral Blood From Women With Scleroderma.

Front. Immunol. 9:1685 doi: 10.3389/fimmu.2018.01685

\section{Soluble HLA-G Expression Inversely Correlates With Fetal Microchimerism Levels in Peripheral Blood From Women With Scleroderma}

\author{
Julie Di Cristofaro ${ }^{1 \dagger}$, Karlin R. Karlmark², Sami B. Kanaan², Doua F. Azzouz', \\ Marina El Haddad², Lucas Hubert3,4,5, Dominique Farge-Bancel'6, Brigitte Granel7,8, \\ Jean Robert Harlé ${ }^{8}$, Eric Hachulla ${ }^{9}$, Etienne Pardoux ${ }^{10}$, Jean Roudier ${ }^{2,11}$, \\ Christophe Picard ${ }^{1,3}$ and Nathalie C. Lambert ${ }^{2 *}$
}

${ }^{1}$ Aix Marseille Univ, CNRS, EFS, ADES, "Biologie des Groupes Sanguins", Marseille, France, ${ }^{2}$ Aix Marseille Univ, INSERM, Autoimmune Arthritis (AA), Marseille, France, ${ }^{3}$ Immunogenetics Laboratory, EFS-Alpes Méditerranée, Marseille, France, ${ }^{4}$ Antibody Therapeutics and Immunotargeting, CRCM, INSERM U1068, Institut Paoli Calmettes, Aix-Marseille Université, Marseille, France, ${ }^{5}$ UM 105, CNRS UMR7258, Marseille, France, ${ }^{6}$ Unité de Médecine Interne Maladies Auto-immunes et Pathologie Vasculaire (UF 04) Hôpital Saint Louis, AP-HP, Centre de Référence des Maladies auto-immunes systémiques Rares d'Île-de-France, FAI2R, EA 3518, Institut Universitaire d'Hématologie, Paris, France, ' UMR-S 1076 Endothélium, Pathologies Vasculaires et Cibles Thérapeutiques - Faculté de Pharmacie, Marseille, France, ${ }^{8}$ AP-HM, Pôle de Médecine Interne, Centre de Compétence PACA Ouest pour la prise en charge des maladies autoimmunes systémiques, Marseille, France, ${ }^{9}$ Service de Médecine Interne, Centre National de Référence de la Sclérodermie Systémique, Hôpital Claude Huriez, Lille, France, ${ }^{10}$ Aix Marseille Univ, CNRS, Centrale Marseille, I2M, Marseille, France, ${ }^{11}$ Rhumatologie, IML, AP-HM, Hôpital Sainte Marguerite, Marseille, France

Women with scleroderma (SSc) maintain significantly higher quantities of persisting fetal microchimerism (FMc) from complete or incomplete pregnancies in their peripheral blood compared to healthy women. The non-classical class-I human leukocyte antigen (HLA) molecule HLA-G plays a pivotal role for the implantation and maintenance of pregnancy and has often been investigated in offspring from women with pregnancy complications. However data show that maternal HLA-G polymorphisms as well as maternal soluble HLA-G (sHLA-G) expression could influence pregnancy outcome. Here, we aimed to investigate the underlying role of maternal sHLA-G expression and $H L A-G$ polymorphisms on the persistence of FMc. We measured SHLA-G levels by enzyme linked immunosorbent assay in plasma samples from 88 healthy women and 74 women with SSc. Male Mc was quantified by DYS14 real-time PCR in blood samples from 58 women who had previously given birth to at least one male child. Furthermore, eight $H L A-G 5^{\prime}$ URR/3'UTR polymorphisms, previously described as influencing HLA-G expression, were performed on DNA samples from 96 healthy women and 106 women with SSc. Peripheral sHLA-G was at lower concentration in plasma from SSc $(76.2 \pm 48.3 \mathrm{IU} / \mathrm{mL})$ compared to healthy women $(117.5 \pm 60.1 \mathrm{JU} / \mathrm{mL}, p<0.0001)$, independently of clinical subtypes, autoantibody profiles, disease duration, or treatments. Moreover, sHLA-G levels were inversely correlated to FMc quantities (Spearman correlation, $p<0.01$ ). Finally, women with SSc had lower sHLA-G independently of the eight HLA-G $5^{\prime}$ URR/3'UTR polymorphisms, although they were statistically more often homozygous than heterozygous for HLA-G 
polymorphism genotypes $-716(\mathrm{G} / \mathrm{T}),-201(\mathrm{G} / \mathrm{A}), 14 \mathrm{bp}$ (ins/del), and +3,142 (G/A) than healthy women. In conclusion, women with SSc display less SHLA-G expression independently of the eight HLA-G polymorphisms tested. This decreased production correlates with higher quantities of persisting FMc commonly observed in blood from SSc women. These results shed some lights on the contribution of the maternal HLA-G protein to long-term persistent fetal $\mathrm{Mc}$ and initiate new perspectives in this field.

\section{Keywords: human leukocyte antigen-G, microchimerism, scleroderma, systemic sclerosis, pregnancy, fetal}

\section{INTRODUCTION}

Scleroderma is a rare, invalidating, and complex autoimmune disease, manifested by vascular abnormalities, extensive collagen deposition in the skin, and fibrotic changes in internal organs. SSc is divided into two forms: limited cutaneous disease (lcSSc) characterized by skin involvement below the elbows and knees and diffuse cutaneous disease ( $\mathrm{dcSSc}$ ) for which skin involvement is more extended, with respectively anticentromere or anti-topoisomerase antibodies (ACA or ATA) as hallmark of each subset (1).

SSc has a strong predilection for women with a peak incidence in women after childbearing years. Moreover, SSc shares some clinical similarities to chronic graft-vs-host disease (cGVHD) (2, 3). Both diseases are characterized by skin, lung, and esophageal involvement and intense fibrosis (2). In cGvHD, donor cells attack the recipient after allogeneic bone marrow stem cell transplantation. This led to the hypothesis that fetal microchimerism (FMc) arising from pregnancy and persisting at long term in the mother may act against the "host" in an "auto/allo" immune reaction and be involved in the development of SSc [for reviews see Ref. $(4,5)$ ].

Although only few studies have demonstrated a role for microchimeric fetal cells in SSc (6-8), many have shown higher levels of fetal Mc in peripheral blood mononuclear cells from women with SSc compared to healthy women $(6,9-12)$. A few propositions have been raised to explain the possible genetic susceptibility for higher passage of fetal cells during pregnancy and/ or maintenance of post-delivery in women with SSc. The host's and/or donor's Human Leukocyte Antigen (HLA) genotype may influence the likelihood of having microchimeric cells in host's blood as previously suggested in SSc and juvenile dermatomyosis $(13,14)$.

A non-classical class-I HLA molecule, HLA-G, described to play a pivotal role for the implantation and maintenance of pregnancy [for review see Ref. (15)], could influence fetal Mc. As the expression of cell-associated and secreted HLA-G antigens was first and mostly described in placenta on villous cytotrophoblasts at the feto-maternal interface $(16,17)$, HLA-Ghas often been investigated in offspring from women with pregnancy complications. Fetal HLA-G is the specific ligand of some receptors (i.e., ILT2, ILT4, and KIR2DL4) present on maternal decidual NK, dendritic cells, and macrophages, which constitute a large part of the immune cells in the uterine compartment, and exerts immunomodulatory functions to secure acceptance of the semiallogenic fetus [for review see Ref. (18)]. Nevertheless, maternal monocytes and dendritic cells express membrane-bound and soluble HLA-G (sHLA-G), respectively (19). The role of maternal HLA-G on the immune tolerance process in pregnancy is poorly understood, although data show that maternal HLA-G polymorphisms as well as maternal sHLA-G expression could influence pregnancy outcome $(20,21)$.

Interestingly, women with pregnancy complications have lower sHLA-G concentration in their plasma $(22,23)$ and higher fetal Mc passage in their circulation than women with healthy pregnancies $(24,25)$. Moreover, women with pregnancy complications are at higher risk to develop later autoimmune diseases, such as scleroderma or rheumatoid arthritis (26-28). This has drawn our attention on a potential role for maternal HLA-G in higher FMc levels in women with SSc.

Human leukocyte antigen-G molecule can be expressed as membrane-bound or soluble form through 7 isoforms generated by alternative splicing: HLA-G1 to G7. HLA-G1 to G4 are membrane bound; only HLA-G1 can be shed from the membrane and also released as sHLA-G1 (29). HLA-G5, G6, and G7 are only soluble forms, HLA-G5 being the most expressed. HLA-G protein expression seems to be modulated by several genetic variations within the coding sequence, the $5^{\prime}$ upstream regulatory region ( $\left.5^{\prime} \mathrm{URR}\right)$ and the $3^{\prime}$ untranslated region ( $\left.3^{\prime} \mathrm{UTR}\right)$ of the $H L A-G$ gene (30-37). Conflicting results for sHLA-G production were reported for the most studied 3'UTR polymorphism, the 14-bp insertion/deletion polymorphism in the exon $8(31,38-40)$.

Thus, in the current study we test whether 1 /women with SSc display lower sHLA-G levels in their plasma than healthy age-matched women, 2/quantities of persistent fetal Mc in their blood inversely correlate with sHLA-G levels, and 3/sHLA-G levels correlate with $H L A-G$ polymorphisms/haplotypes. We recruited 96 healthy women and 106 women with SSc, quantified sHLA-G in plasma samples from respectively 88 and 74 women by enzyme linked immunosorbent assay (ELISA) and analyzed 8 polymorphisms in the $5^{\prime} \mathrm{URR}$ and $3^{\prime} \mathrm{UTR}$ of the $H L A-G$ gene, including the most described 14-bp insertion/deletion to determine UTR1-8 haplotypes. In parallel, using DYS14 real-time PCR assays, we analyzed male microchimerism of fetal origin in peripheral blood samples from 58 women who had given birth to at least one male child.

\section{MATERIALS AND METHODS}

\section{Subjects}

A total of 106 women with SSc were recruited in four French hospitals (St. Louis hospital in Paris; Claude Huriez Hospital in Lille; La Conception and Nord Hospital in Marseille, France). All patients met the requirements of LeRoy for SSc (41), with 48 
having diffuse cutaneous disease (dcSSc) and 55 limited cutaneous disease $(\mathrm{lcSSc})$. Three of them were only defined as having SSc with no indication of clinical subtype. Women were majorly Caucasian (80.2\%), then African (14.2\%), and Asian (5.6\%). Their mean age at blood draw was 54.4 years old [range:16-75].

In parallel, 96 healthy women with no family history of autoimmune disease were recruited in the Centre d'Examen de Santé de l'Assurance Maladie (CESAM), Marseille, France. They were majorly Caucasian (94.8\%), then African (3.1\%), and Asian (2.1\%). Their mean age at blood draw was 50.8 years old [range: 36-69]. Questionnaires with detailed information about history of source of male Mc (transfusion, history of pregnancy, and older brother) were filled in for each participant of the study. For one patient, we could not obtain all information.

\section{Ethics Statement}

This study has received the approval from the French Ethical Committee Marseille 2 and is registered at the INSERM (Biomedical Research Protocol number RBM-04-10). All participants signed written consent forms according to the Declaration of Helsinki (42).

\section{sHLA-G Measurement}

Plasma samples from 88 healthy women and 74 women with SSc were obtained after gradient centrifugation of whole peripheral blood on Ficoll-Hypaque 1077 (Sigma-Aldrich, St. Louis, MO, USA). Plasma were stored at $-40^{\circ} \mathrm{C}$ until tested. Measurement of both shed HLA-G1 and sHLA-G5 isoforms was performed in duplicate on plasma samples from 88 healthy women and 74 women with SSc using the ELISA assay kit (EXBIO/Biovendor, Karásek, Czech Republic; capture antibody: MEM-G/9), defined at the "Wet-Workshop for the Quantification of sHLA-G" in 2004 (43) according to the manufacturer's instructions. It is to note that the current assay does not allow to distinguish which isoform HLA-G1 or G5 is the most expressed. sHLA-G standard was diluted to obtain a calibrator curve within a range from 3.91 to 125 International units/mL (IU/mL) for sHLA-G ELISA. The total protein concentration levels were expressed in $\mathrm{IU} / \mathrm{mL}$ of plasma.

\section{DNA Sample Handling}

DNA from 96 healthy women and 106 women with SSc was isolated from $350 \mu \mathrm{l}$ of blood samples by commercially available method (Qiagen EZ1). DNA concentrations were quantified by Biodrop instrument according to the manufacturer's protocol and further by beta-globin-specific Q-PCR as previously described (44). DNA samples from 58 women who had given birth to at least 1 male child were further analyzed for microchimerism studies (38 SSc and 20 healthy women). All DNA samples were sent to the Immunogenetic laboratory at the French Blood Transfusion Department (EFS), Marseille, France, for analyzing the 5'URR and 3'UTR polymorphisms (see below).

\section{Quantification of Male Mc of Fetal Origin}

Male Mc was quantified by a standardized real-time PCR for a Y-chromosome-specific sequence DYS14 on a Light Cycler ${ }^{\circledR}$ with Light Cycler ${ }^{\circledR}$ Fast Start DNA Master PLUS Reaction kits (Roche,
Indianapolis, IN, USA) as previously described (12). Sensitivity of the DYS14 assay was of 1 genome equivalent ( $1 \mathrm{gEq}$ ) of male cell in a background of 20,000 gEq female cells. Each DNA sample from whole peripheral blood was then tested for DYS14 amplification in 10 aliquots of DNA equivalent of 20,000 cells (=132 ng with the conversion of 1 cell $=6.6 \mathrm{pg}$ ). The amount of male DNA was expressed as the number of gEq of male cells per million (M) of gEq of female cells ( $\mathrm{gEq} / \mathrm{M})$.

There was no occurrence of a positive amplification in any of the negative controls (no DNA template). A triplicate of male DNA at 10 or $50 \mathrm{gEq}$, in a background of $20,000 \mathrm{gEq}$, was systematically run in each plate and served as inter-plate reference standard and positive control.

Presence of male DNA has been tested in peripheral blood from 58 women ( 38 women with SSc and 20 healthy women) who had previously given birth to at least one son. Obstetrical and clinical characteristics are detailed in Tables $\mathbf{1}$ and 2, respectively.

\section{HLA-G 5'URR and 3'UTR Genotyping and UTR Haplotype Estimation}

A home-made primer extension method, as previously described, was used to simultaneously analyze four SNPs in the 5'URR region (-725C/G/T rs1233334, -716 G/T rs2249863, -201 G/A rs1233333, and $-56 \mathrm{C} / \mathrm{T}$ rs17875397) and four polymorphisms in the $3^{\prime} \mathrm{UTR}$ region (ins/del exon $8 \mathrm{rs} 66554220 ; 3142 \mathrm{C} / \mathrm{G}$ rs1063320; 3187G/A rs9380142; and 3196C/G rs1610696) (45). $H L A-G$ genotypes were analyzed using GeneMapper 4.0 with specific detection parameters. UTR HLA-G haplotypes were estimated using an EM algorithm from the Gene (46) program and confirmed using the EM and ELB algorithms from the Arlequin v3.5.1.2 package. Data were analyzed and interpreted as previously described $(45,47)$.

\section{Statistical Analyses}

Mann-Whitney test was applied to compare sHLA-G dosages (expressed in $\mathrm{IU} / \mathrm{mL}$ ) between patients and controls, independently or according to HLA-G genetic status, SSc-associated treatments, age of probands or disease duration.

To quantify the degree to which sHLA-G quantities is related to fetal male DNA quantities, we excluded women with history of blood transfusion, or for whom we did not have transfusion information to not confound natural (arising from pregnancy) and iatrogenic (from transplantation) sources of male Mc. Nevertheless, to test whether male DNA levels arising from pregnancy correlated with sHLA-G levels in plasma, we did not eliminate women who had spontaneous or induced abortions additionally to their son, although we did not know the sex of the fetus. Correlation was assessed with Spearman rank correlation test. $P$ values less than 0.05 were considered significant. Statistical analyses were conducted using GraphPad Prism 6 (La Jolla, CA, USA).

Significant deviations from expected values at HardyWeinberg equilibrium (HWE) were tested for each polymorphisms using Chi square "goodness of fit" test (http://vassarstats.net). As for two SNPs HWE was not respected (-201 (A/G), -56 $(\mathrm{C} / \mathrm{T}))$ in the healthy population, and numbers were small, we did not use the classical $\chi^{2}$ for evaluating whether women with 
TABLE 1 | Obstetrical and clinical characteristics of women with SSc quantified for male DNA and soluble HLA-G (sHLA-G) levels.

\begin{tabular}{|c|c|c|c|c|c|c|c|c|c|}
\hline SSc women & $\begin{array}{l}\text { Age at blood } \\
\text { draw (years) }\end{array}$ & $\begin{array}{l}\text { Disease duration at } \\
\text { blood draw (years) }\end{array}$ & $\begin{array}{l}\text { \# of } \\
\text { sons }\end{array}$ & $\begin{array}{l}\text { Age of last } \\
\text { son (years) }\end{array}$ & $\begin{array}{c}\text { Spontaneous or } \\
\text { induced abortions }\end{array}$ & $\begin{array}{c}\text { Blood } \\
\text { transfusions }\end{array}$ & $\begin{array}{l}\text { \# of older } \\
\text { brothers }\end{array}$ & $\begin{array}{l}\text { Male Mc }{ }^{\mathrm{a}} \\
(\mathrm{gEq} / \mathrm{M})\end{array}$ & sHLA-Gb (IU) \\
\hline SSc01 & 63 & 10 & 1 & 25 & 1 & Ukn ${ }^{c}$ & 0 & $22.5^{d}$ & 84.0 \\
\hline SSc02 & 60 & 5 & 1 & 35 & 0 & 0 & 0 & 0.5 & 23.6 \\
\hline SSc03 & 45 & 2 & 1 & 20 & 0 & 0 & 0 & 12.7 & 17.1 \\
\hline $\mathrm{SScO} 4$ & 58 & 1 & 1 & 30 & 0 & 0 & 1 & 1.6 & 49.2 \\
\hline SSc05 & 73 & 6 & 2 & Ukn & 0 & 0 & 0 & 0 & 119.7 \\
\hline SSc06 & 49 & 5 & 1 & 9 & 1 & 0 & 0 & 4.5 & 83.5 \\
\hline SSc07 & 78 & 23 & 1 & 56 & 0 & 0 & 0 & 2.6 & 83.0 \\
\hline SSc08 & 64 & 1 & 6 & Ukn & 0 & 0 & 1 & 0.0 & 62.2 \\
\hline SSc09 & 55 & 6 & 3 & 33 & 0 & $1^{e}$ & 0 & 12.5 & 25.2 \\
\hline SSc10 & 45 & 5 & 2 & Ukn & 1 & 0 & 3 & 10.0 & 21.3 \\
\hline SSc11 & 51 & 4 & 2 & 15 & 1 & 0 & 1 & 4.3 & 19.0 \\
\hline SSc12 & 60 & 9 & 1 & 36 & 0 & 0 & 1 & 2.7 & 116.9 \\
\hline SSc13 & 62 & 6 & 1 & 37 & 0 & 0 & 1 & 0.0 & 52.8 \\
\hline SSc14 & 47 & 18 & 1 & 16 & 0 & 0 & 0 & 14.0 & 90.8 \\
\hline SSc15 & 50 & 5 & 2 & 17 & 0 & 0 & 1 & 0.0 & 61.3 \\
\hline SSc16 & 58 & 5 & 2 & 33 & 0 & 4 & 0 & 4.5 & 66.2 \\
\hline SSc17 & 66 & 9 & 1 & 37 & 3 & 0 & 1 & 0.0 & 31.0 \\
\hline SSc18 & 53 & 3 & 1 & 19 & 1 & 0 & 1 & 0.0 & 142.0 \\
\hline SSc19 & 62 & 23 & 1 & Ukn & 1 & 0 & 0 & 0.0 & 95.9 \\
\hline SSc20 & 72 & 6 & 1 & Ukn & 2 & Ukn & 2 & 0.0 & 177.2 \\
\hline SSc21 & 64 & 5 & 2 & Ukn & 0 & 1 & 1 & 0.0 & 176.7 \\
\hline SSc22 & 35 & 5 & 1 & 10 & 0 & 0 & 2 & 0.0 & 123.9 \\
\hline SSc23 & 48 & 0 & 2 & 20 & 0 & 0 & 3 & 0.0 & 87.9 \\
\hline SSc24 & 43 & 2 & 2 & Ukn & 1 & 1 & 0 & 0.0 & 98.9 \\
\hline SSc25 & 57 & 9 & 2 & Ukn & 5 & 1 & 3 & 0.0 & 54.2 \\
\hline SSc26 & 49 & 12 & 1 & 44 & Ukn & 0 & Ukn & 9.7 & 25.9 \\
\hline SSc27 & 40 & 13 & 1 & 15 & 2 & 0 & 0 & 0.0 & 47.1 \\
\hline SSc28 & 66 & 16 & 2 & 37 & 0 & 0 & 2 & 0.0 & 34.5 \\
\hline SSc29 & 62 & 13 & 1 & 40 & 2 & Ukn & 0 & 2.3 & 67.5 \\
\hline SSc30 & 61 & 1 & 1 & 32 & 1 & 0 & 1 & 7.1 & 16.3 \\
\hline SSc31 & 52 & 2 & 1 & 32 & 0 & 0 & 1 & 0.0 & 64.2 \\
\hline SSc32 & 45 & 22 & 1 & 24 & 0 & 0 & 1 & 0.0 & 89.2 \\
\hline SSc33 & 37 & 0 & 1 & 7 & 0 & 0 & 1 & 0.0 & 164.0 \\
\hline SSc34 & 54 & 17 & 1 & 26 & 0 & 0 & 0 & 0.0 & 76.3 \\
\hline SSc35 & 56 & 12 & 1 & 17 & 1 & 0 & 0 & 53.2 & 49.8 \\
\hline SSc36 & 40 & 3 & 1 & 15 & 1 & 0 & 2 & 0.0 & 92.8 \\
\hline SSc37 & 53 & 19 & 2 & 25 & 2 & 0 & 0 & 0.5 & 37.5 \\
\hline SSc38 & 75 & 25 & 4 & 33 & 1 & 2 & 0 & 0.0 & 106.3 \\
\hline
\end{tabular}

aMale microchimerism is expressed in genome equivalent of male cells per million of maternal cells ( $g$ Eq/M).

${ }^{b}$ Quantities of SHLA-G are expressed in International Units per $m L$ of plasma (IU/mL).

'Unknown data are abbreviated with ukn.

${ }^{d}$ Positive values for male $\mathrm{Mc}$ are in bold.

eWomen who had an history of transfusion are in bold and were excluded from statistical analysis, as well as women with unknown data for blood transfusion.

SSc were less often heterozygous for $H L A-G$ polymorphisms than healthy women, but rather the Bayesian statistical method ( $\mathrm{R}$ software version 3.0.2.10), as recommended in such cases (48). $P$ values were further corrected for multiple comparison tests by Benjamini-Hochberg correction (49).

Chi-square " $\chi$ " tests with Benjamini-Hochberg corrections were used to compare UTR haplotype frequencies between healthy women and women with SSc.

\section{RESULTS}

\section{Women With SSc Displayed Lower sHLA-G in Their Plasma Compared to Healthy Women}

Soluble HLA-G (shed HLA-G1 and sHLA-G5) could be detected by the ELISA technique defined at the "Wet-Workshop for the
Quantification of sHLA-G" in all plasma samples (43), with quantities ranging from 8.8 International Units (IU) per $\mathrm{mL}$ of plasma to $187.9 \mathrm{IU} / \mathrm{mL}$ in samples from women with SSc and from 13.5 to $262.5 \mathrm{IU} / \mathrm{mL}$ in samples from healthy women (Figure 1).

Women with SSc had significantly lower quantities of sHLA-G than healthy women in their plasma with respectively a mean of $76.2 \mathrm{IU} / \mathrm{mL}$ compared to $117.5 \mathrm{IU} / \mathrm{mL}(p<0.0001)$.

\section{Lower sHLA-G Was Independent of Clinical Subtypes, Autoantibody Profiles, Disease Duration, Treatments, or HLA-G 5'URR/3'UTR Polymorphisms}

Quantities of sHLA-G were identical whether women with SSc had diffuse or limited cutaneous SSc (Figure 2A), were positive for ATA or anti-centromere antibodies (ACA) or were negative for both autoantibodies (Figure 2B). No correlation was observed 
TABLE 2 | Obstetrical and clinical characteristics of healthy women quantified for male DNA and soluble HLA-G (sHLA-G) levels.

\begin{tabular}{|c|c|c|c|c|c|c|c|c|}
\hline Healthy women (HW) & $\begin{array}{l}\text { Age at blood } \\
\text { draw (years) }\end{array}$ & \# of sons & $\begin{array}{l}\text { Age of last } \\
\text { son (years) }\end{array}$ & $\begin{array}{c}\text { Spontaneous or } \\
\text { induced abortions }\end{array}$ & $\begin{array}{c}\text { Blood } \\
\text { transfusions }\end{array}$ & $\begin{array}{l}\text { \# of older } \\
\text { brothers }\end{array}$ & $\begin{array}{l}\text { Male Mc } \\
(\mathrm{gEq} / \mathrm{M})\end{array}$ & sHLA-Gb (IU) \\
\hline HW01 & 37 & 1 & 4 & 0 & 0 & 0 & $0.61^{\mathrm{C}}$ & 119.7 \\
\hline HWO2 & 57 & 2 & 23 & 1 & 0 & 0 & 0 & 26.2 \\
\hline HW03 & 58 & 1 & 22 & 0 & 0 & 2 & 0 & 81.2 \\
\hline HW04 & 58 & 1 & 40 & 3 & $\mathbf{1}^{\mathrm{d}}$ & 2 & 2.3 & 140.7 \\
\hline HW05 & 42 & 1 & 15 & 2 & 0 & 0 & 0 & 112.1 \\
\hline HW06 & 38 & 1 & 9 & 0 & 0 & 0 & 0 & 13.5 \\
\hline HW07 & 60 & 1 & 32 & 1 & 0 & 0 & 0 & 117.8 \\
\hline HW08 & 54 & 1 & 26 & 0 & 0 & 0 & 0 & 150.4 \\
\hline HW09 & 53 & 1 & 38 & 0 & 0 & 3 & 0 & 37.3 \\
\hline HW10 & 66 & 1 & 35 & 0 & 0 & 0 & 0 & 65.0 \\
\hline HW11 & 47 & 1 & 23 & 0 & 0 & 3 & 0 & 212.9 \\
\hline HW12 & 54 & 2 & 21 & 1 & 0 & 0 & 0 & 157.4 \\
\hline HW13 & 40 & 2 & 9 & 0 & 0 & 0 & 0 & 49.3 \\
\hline HW14 & 54 & 1 & 25 & 0 & 2 & 1 & 0 & 170.2 \\
\hline HW15 & 46 & 1 & 17 & 1 & 0 & 1 & 0 & 35.6 \\
\hline HW16 & 49 & 1 & 24 & 0 & 0 & 0 & 0 & 94.6 \\
\hline HW17 & 41 & 2 & 13 & 1 & 0 & 1 & 1.07 & 60.0 \\
\hline HW18 & 50 & 1 & 19 & 1 & 0 & 0 & 0 & 76.5 \\
\hline HW19 & 59 & 3 & 25 & 2 & 0 & 0 & 0 & 62.2 \\
\hline HW2O & 49 & 1 & 22 & 1 & 0 & 1 & 0 & 228.0 \\
\hline
\end{tabular}

aMale microchimerism is expressed in genome equivalent of male cells per million of maternal cells ( $g$ Eq/M).

${ }^{b}$ Quantities of SHLA-G are expressed in International Units per $\mathrm{mL}$ of plasma (IU/mL).

cPositive values for male Mc are in bold.

${ }^{d}$ Women who had an history of transfusion are in bold and were excluded from statistical analysis.

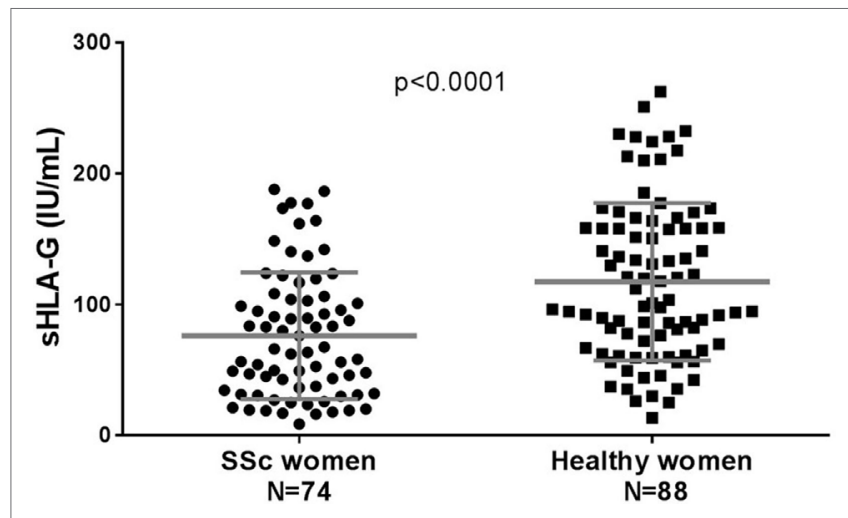

FIGURE 1 | Quantification of soluble HLA-G (sHLA-G) in plasma from healthy and SSc women. Quantification of SHLA-G is expressed in International Units per $\mathrm{mL}$ of plasma (IU/mL). Black circles represent values for women with SSc and black squares represent values for healthy women. Means and SDs are given for each scatter plot by gray bars. $P$ value is calculated by MannWhitney test.

between sHLA-G levels and the age of probands or disease duration (data not shown).

Soluble HLA-G dosages were not different whether women were under immunosuppressive therapies (cyclophosphamide, methotrexate, etc.) with or without anti-inflammatory medications (non-steroidal or corticosteroids, etc.) or had only drugs to treat consequences of the disease, such as vasodilatator therapies (calcium channel blockers, angiotensin converting enzyme inhibitors, etc.), antifibrotic agents (colchicine, etc.), or others (i.e., proton pump inhibitors for gastroesophageal reflux) (Figure 2C).
Finally, the significant decrease of sHLA-G expression observed in SSc women compared to healthy women seemed independent from the eight $H L A-G 5^{\prime} \mathrm{URR} / 3^{\prime} \mathrm{UTR}$ tested polymorphisms as the difference remained significant when patients and controls were separated according to their $H L A-G$ genotypes for each polymorphic site (Figure 3).

\section{Lower sHLA-G Expression Correlated With Higher Levels of Male Microchimerism}

In women with SSc, sHLA-G expression was inversely correlated with levels of fetal $\mathrm{Mc}$ in their peripheral blood as illustrated in Figure 4 [Spearman correlation coefficient $r=-0.46,95 \%$ confidence interval $(-0.71$ to -0.10$), p=0.01$ ]. Quantities of male DNA in maternal blood seemed to be independent from the number of sons, the number of years since the birth of last son or the disease duration (Table 1). Male Mc observed here is more probably from pregnancy than from an older brother, since $69 \%$ of women with SSc who had male Mc did not have an older brother (Table 1).

\section{Women With SSc Displayed a Lack of Heterozygosity for HLA-G Polymorphisms Compared to Healthy Women}

A lack of heterozygosity among genotypes was observed in the SSc population with statistical significance for four polymorphisms: $-716(\mathrm{G} / \mathrm{T}),-716(\mathrm{G} / \mathrm{T}),-201$ (G/A), exon 8 (Ins/Del), and $+3,142(\mathrm{G} / \mathrm{C})$, even after correction for multiple comparisons (Table 3). However, none of the polymorphisms described here displayed allelic frequency differences between women with SSc and healthy women. 

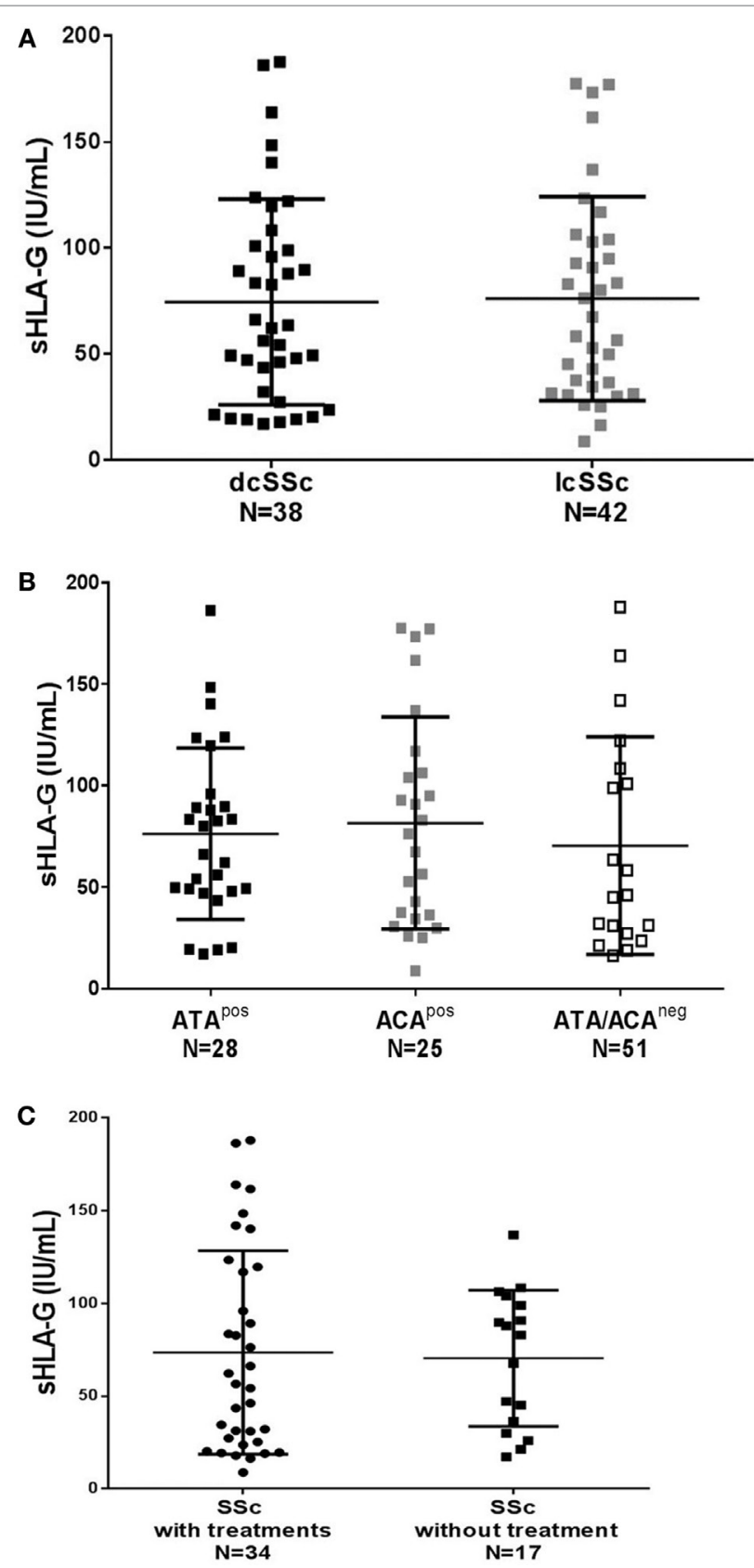

FIGURE 2 | Quantification of soluble HLA-G (sHLA-G) in plasma from women with SSc divided according to (A) their clinical status: black squares represent values for women with diffuse cutaneous SSc (dcSSc), gray squares represent values for women with limited cutaneous SSc (ICSSc); (B) their autoantibody status: black squares represent values for women with SSc positive for anti-topoisomerase antibodies (ATA ${ }^{\text {pos }}$ ), gray squares represent values for women with anti-centromere antibodies (ACA ${ }^{\text {pos }}$ ), and white squares represent values for women negative for both autoantibodies (ATA/ACA ${ }^{\text {neg) }}$; and $(\mathbf{C})$ their treatments: black circles represent values for women who are under immunosuppressive therapies and/or antiinflammatory medications, labeled "with treatments"; black squares represent values for women who have only drugs to treat consequences of the disease and labeled "without treatments." Means and SDs are given for each scatter plot by gray bars $P$ values are calculated by Mann-Whitney test in $(\mathbf{A}, \mathbf{C})$ and one way-ANOVA test in (B) and are not significant for any of the graphs ( $p=0.85, p=0.49$, and $p=0.75$, respectively).
As there was significantly more individuals of African and Asian origin in cases than in controls $(P<0.01)$, we performed the same analysis by considering only Caucasian individuals. Results were similar than the ones with all cases and controls (Table S1 in Supplementary Material).

\section{Frequencies of UTR Haplotypes in Healthy Women and Women With SSc}

Human leukocyte antigen- $G$ haplotypes were defined by four SNPs in the $5^{\prime}$ URR and four polymorphisms in the $3^{\prime}$ UTR are named UTR. UTR frequencies between women with SSc and healthy women (Table 4), did not display any significant difference, although a tendency for an increase of the UTR2 haplotype in SSc, particularly in dcSSc was observed, none of the $p$ values remained significant after correction for multiple tests. Similarly, the small decrease for the UTR5 and UTR7 haplotypes in SSc, particularly in dcSSc, did not remain significant after correction.

\section{DISCUSSION}

The HLA-G molecule has tolerogenic functions and its role has been described in transplantation, human reproduction, and more recently in some rheumatologic diseases, including SSc [for review see Ref. (50)]. In the present study, we focus on the initially described role of HLA-G expression on immune tolerance during pregnancy. We hypothesized that the observation described by our group and others, that parous women with SSc maintain higher levels of fetal Mc compared to matched healthy controls, is due to an impaired expression of maternal sHLA-G. Studies on preeclampsia (PE) support our hypothesis as women with pregnancies complicated with PE have lower levels of sHLA-G in their blood in the second and third trimester compared to controls [for review see Ref. (51)]. In parallel to low sHLA-G production, pregnancies with $\mathrm{PE}$ are associated with higher passage of circulating fetal DNA and fetal cells in maternal peripheral blood $(24,25)$.

In the current study, we validate the hypothesis that women with SSc produce less sHLA-G in their plasma than healthy women. Quantities are low and at comparable levels whether women with SSc have a dcSSc or lcSSc and whether they produce ATA, ACA, or none of those antibodies. Notably, treatments associated with SSc do not seem to have an influence on sHLA-G levels, as women who had only drugs treating consequences of the disease (i.e., gastroesophageal reflux, etc.) have levels as low as women under immunosuppressive therapies and/or anti-inflammatory medications. The ELISA used is a sandwich enzyme immunoassay for the quantitative measurement of any soluble forms of HLA-G. Therefore, it measures the shed sHLA-G1 and the secreted HLAG5 isoform without distinction and we cannot tell at this point which one of the isoform is less present in our measurements.

To our knowledge, only two studies have recently evaluated sHLA-G in sera/plasma samples from patients with SSc $(52,53)$. The first one showed a tendency for lower levels in patients but failed to find statistical difference. The second one showed a significant increased expression in patients. Contradictory results could come from the relatively small number of patients $[N=35$ in Ref. (53)] and/or of healthy controls tested in both studies $[N=32$ and 40 , respectively $(52,53)]$. 


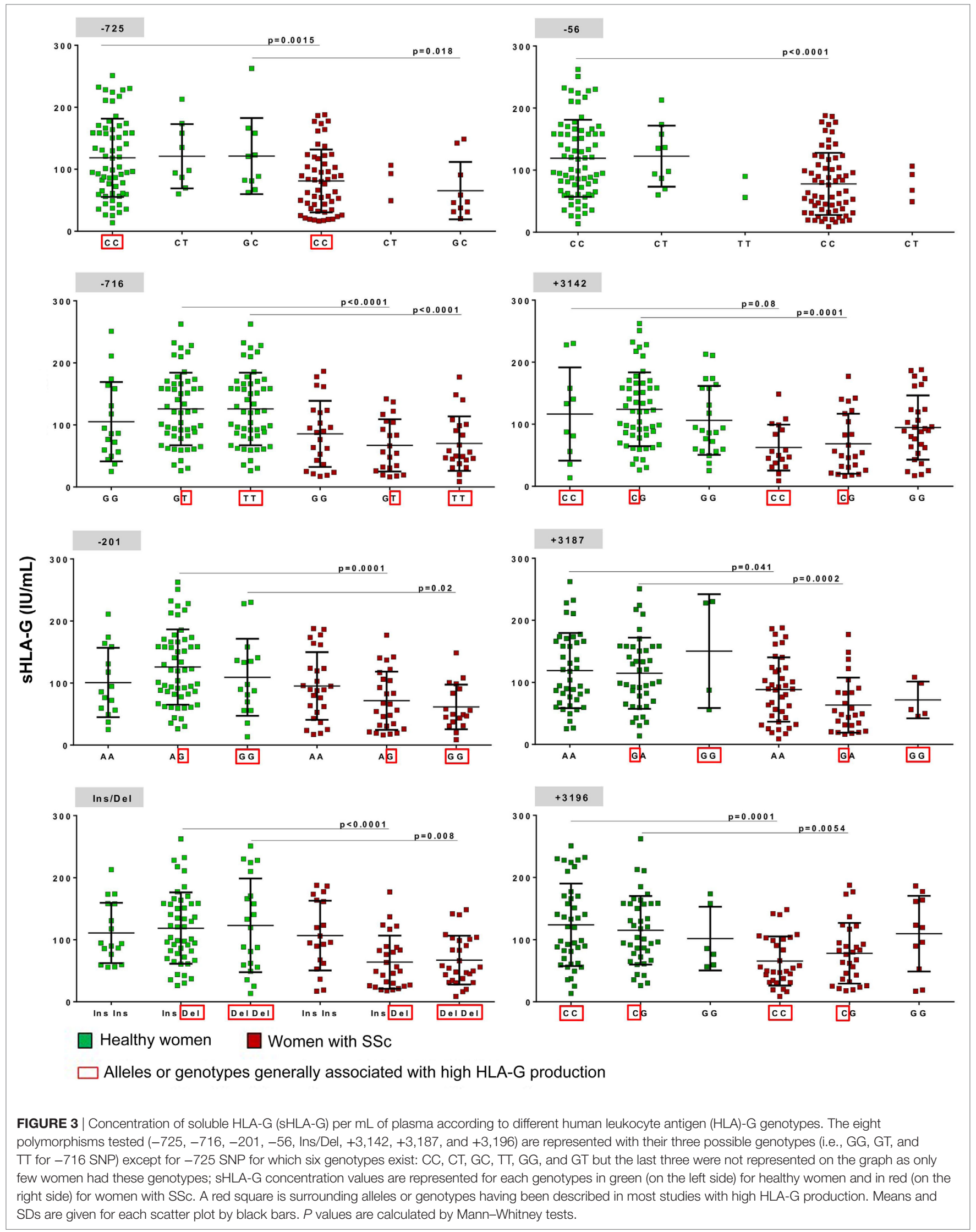




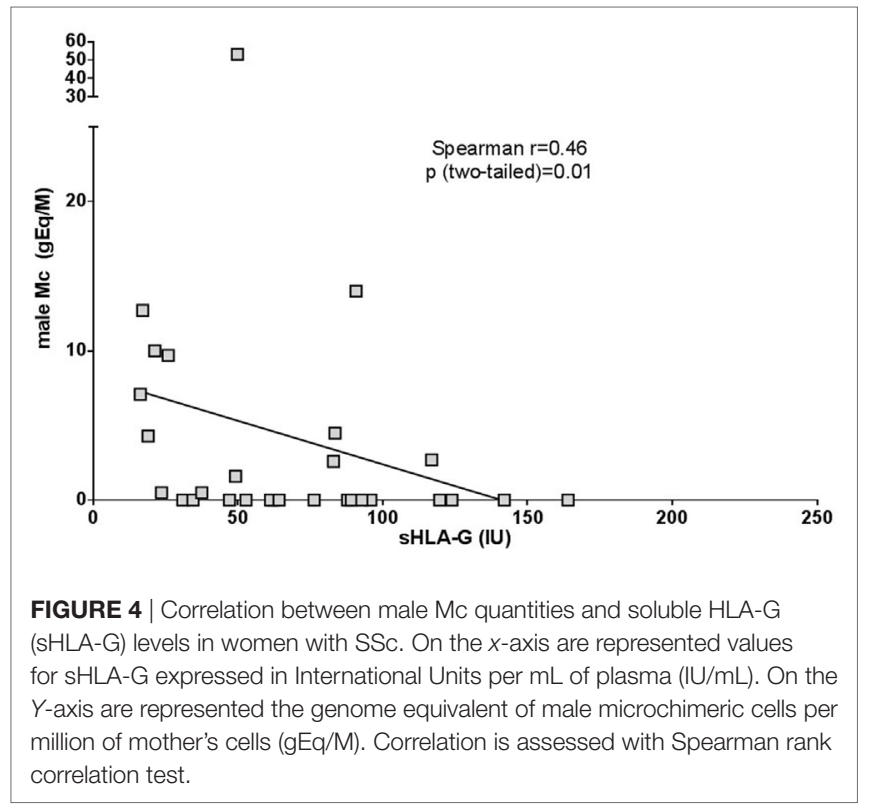

Although several $H L A-G$ polymorphisms have been described as being associated with reduced production of sHLA-G, we could not find any association with $H L A-G$ genetic polymorphism and SSc or sHLA-G expression in women with SSc. Our results are concordant with those of Nilsson et al. describing no association with $H L A-G$ haplotype or with ins/del polymorphism with increased risk of developing severe preeclampsia/eclampsia in a cohort of more than 900 women (54). Nevertheless, women with PE have low levels of sHLA-G as reported in several studies $(20,55)$.

As our study is the first to test these polymorphisms in SSc (except Ins/Del), it would be of great value to confirm our data on large cohorts of patients with SSc and on other ethnic groups. Nevertheless, our data suggest that the eight polymorphisms tested in the 5'URR and in the 3'UTR are not sufficient to predict any decreased production of sHLA-G observed in SSc; other SNPs in regulatory regions might contribute to sHLA-G expression modulation. DNA methylation is an important mechanism for regulating gene expression and a few reports suggest that methylation of the $H L A-G$ promoter is associated with lower secretion of HLA-G in women with preeclampsia $(56,57)$. Moreover, our results showing that women with SSc who carry $H L A-G$ alleles commonly associated with high sHLA-G levels have low sHLA-G levels, comfort a possible epigenetic regulation of sHLA-G production on 5' URR or 3'UTR.

Although patients did not have a particular $H L A-G$ allele over-represented, they were statistically more often homozygous than heterozygous for HLA-G polymorphism genotypes (i.e., Ins/Ins or Del/Del > Ins/Del). High heterozygosity for MHC genes is classically observed in the general healthy population and may be enforced by natural selection for a higher genetic diversity (58). On the opposite homozygotic carriers could be less resistant to broader spectrum of pathogens as they have less antigen presentation possibilities than heterozygotic carriers. A recent study showed that women homozygous for -716 HLA-G SNP are at higher risk for spontaneous abortion (59). This confirms the disadvantage of carrying homozygous $H L A-G$
TABLE 3 | Genotype and allele frequencies of eight human leukocyte antigen-G (HLA-G) polymorphisms in healthy and SSc women.

\begin{tabular}{|c|c|c|c|c|c|c|}
\hline \multirow[t]{2}{*}{$\begin{array}{l}\text { HLA-G } \\
\text { polymorphisms }\end{array}$} & \multirow[t]{2}{*}{$\begin{array}{l}\text { Genotypes } \\
\text { or alleles }\end{array}$} & \multicolumn{2}{|c|}{$\begin{array}{l}\text { Healthy } \\
\text { women } \\
N=96\end{array}$} & \multicolumn{2}{|c|}{$\begin{array}{c}\text { SSc } \\
\text { women } \\
N=106\end{array}$} & \multirow[t]{2}{*}{$\begin{array}{l}P \text { values } \\
\text { cases vs } \\
\text { controls }\end{array}$} \\
\hline & & $N$ & $\%$ & $N$ & $\%$ & \\
\hline \multirow{9}{*}{-725} & $\mathrm{CC}$ & 68 & 70.8 & 76 & 71.7 & \multirow{6}{*}{$n s^{c}$} \\
\hline & $\mathbf{C T}^{\mathrm{b}}$ & 10 & 10.4 & 8 & 7.5 & \\
\hline & GC & 13 & 13.5 & 20 & 18.9 & \\
\hline & $\pi$ & 3 & 3.1 & 0 & 0.0 & \\
\hline & $G G$ & 1 & 1.0 & 2 & 1.9 & \\
\hline & GT & 1 & 1.0 & 0 & 0.0 & \\
\hline & $\mathrm{C}$ & 159 & 82.8 & 180 & 84.9 & \multirow{3}{*}{$s$} \\
\hline & $G$ & 16 & 8.3 & 24 & 11.3 & \\
\hline & $\mathrm{T}$ & 17 & 8.9 & 8 & 3.8 & \\
\hline \multirow{5}{*}{-716} & GG & 19 & 19.8 & 37 & 34.9 & \\
\hline & GT & 57 & 59.4 & 37 & 34.9 & $P=0.0003$ \\
\hline & $\pi$ & 20 & 20.8 & 32 & 30.2 & $P c=0.002$ \\
\hline & $G$ & 95 & 49.5 & 116 & 54.7 & ns \\
\hline & $\mathrm{T}$ & 97 & 50.5 & 96 & 45.3 & \\
\hline \multirow{5}{*}{-201} & $\mathrm{AA}$ & 16 & 16.7 & 35 & 33.0 & \\
\hline & GA & 60 & 62.5 & 45 & 42.5 & $P=0.002$ \\
\hline & $\mathrm{GG}$ & 20 & 20.8 & 26 & 24.5 & $P c=0.006$ \\
\hline & $A$ & 92 & 47.9 & 115 & 54.2 & \multirow[t]{2}{*}{ ns } \\
\hline & G & 100 & 52.1 & 97 & 45.8 & \\
\hline \multirow{5}{*}{-56} & $\mathrm{CC}$ & 82 & 85.4 & 98 & 92.5 & \multirow{3}{*}{ ns } \\
\hline & CT & 11 & 11.5 & 8 & 7.5 & \\
\hline & $\pi$ & 3 & 3.1 & 0 & 0.0 & \\
\hline & $\mathrm{C}$ & 175 & 91.1 & 204 & 96.2 & $n s$ \\
\hline & $\mathrm{T}$ & 17 & 8.9 & 8 & 3.8 & \\
\hline \multirow{5}{*}{ Ins/Del } & Ins Ins & 18 & 18.8 & 25 & 23.6 & \\
\hline & Ins Del & 54 & 56.3 & 42 & 39.6 & $P=0.01$ \\
\hline & Del Del & 24 & 25.0 & 39 & 36.8 & $P c=0.02$ \\
\hline & Ins & 90 & 46.9 & 92 & 43.4 & \multirow[t]{2}{*}{ ns } \\
\hline & Del & 102 & 53.1 & 120 & 56.6 & \\
\hline \multirow{5}{*}{$+3,142$} & $\mathrm{CC}$ & 13 & 13.5 & 24 & 22.6 & \\
\hline & GC & 57 & 59.4 & 41 & 38.7 & $P=0.002$ \\
\hline & $\mathrm{GG}$ & 26 & 27.1 & 41 & 38.7 & $P c=0.008$ \\
\hline & $\mathrm{C}$ & 83 & 43.2 & 89 & 42.0 & \multirow[t]{2}{*}{ ns } \\
\hline & G & 109 & 56.8 & 123 & 58.0 & \\
\hline \multirow{5}{*}{$+3,187$} & $\mathrm{AA}$ & 46 & 47.9 & 60 & 56.6 & \multirow{3}{*}{ ns } \\
\hline & GA & 46 & 47.9 & 41 & 38.7 & \\
\hline & $\mathrm{GG}$ & 4 & 4.2 & 5 & 4.7 & \\
\hline & A & 138 & 71.9 & 161 & 75.9 & \multirow[t]{2}{*}{ ns } \\
\hline & G & 54 & 28.1 & 51 & 24.1 & \\
\hline \multirow{5}{*}{$+3,196$} & $\mathrm{CC}$ & 47 & 49.0 & 44 & 41.5 & \multirow{3}{*}{ ns } \\
\hline & CG & 43 & 44.8 & 48 & 45.3 & \\
\hline & GG & 6 & 6.3 & 14 & 13.2 & \\
\hline & C & 137 & 71.4 & 136 & 64.2 & \multirow[t]{2}{*}{ ns } \\
\hline & $G$ & 55 & 28.6 & 76 & 35.8 & \\
\hline
\end{tabular}

a $P$ values $(P)$ are calculated by Bayesian tests and $P_{C}(P$ corrected) values correspond to multiple comparison correction by Benjamini-Hochberg test (see Materials and Methods). ${ }^{b}$ Genotypes in bold are heterozygous, comparisons are made between heterozygous polymorphisms and homozygous polymorphisms (i.e., for -716 (G/T): GT vs GG + TT). ${ }^{c}$ Non significant $p$ values are noted $n s$.

polymorphisms for success of reproduction and may be related to the consequence that women with pregnancy complications are at higher risk to develop later SSc. 
TABLE 4 | Frequencies of UTR haplotypes in healthy women and women with SSc.

\begin{tabular}{|c|c|c|c|c|c|c|c|c|c|c|c|c|c|}
\hline \multirow[t]{2}{*}{ UTR } & \multirow{2}{*}{$\begin{array}{c}\text { Coding allele } \\
\text { Human } \\
\text { leukocyte } \\
\text { antigen-G }\end{array}$} & \multicolumn{5}{|c|}{ 5'URR } & \multicolumn{3}{|c|}{ 3'UTR } & \multicolumn{4}{|c|}{ Haplotype number, frequency (\%) } \\
\hline & & -725 & -716 & -201 & -56 & $14 b p$ & 3,142 & 3,187 & 3,196 & $\begin{array}{l}\text { Healthy women, } \\
\qquad \begin{array}{c}N=96 \\
192 \text { hapl. }\end{array}\end{array}$ & $\begin{array}{l}\text { SSc women, } \\
\qquad \begin{array}{c}N=106 \\
212 \text { hapl. }\end{array}\end{array}$ & $\begin{array}{c}\text { dcSSc women, } \\
N=48 \\
96 \text { hapl. }\end{array}$ & $\begin{array}{c}\text { IcSSc women, } \\
N=55 \\
110 \text { hapl. }\end{array}$ \\
\hline UTR-1 & 01:01 & C & $\mathbf{T}$ & G & C & Del & C & G & C & $51(26.6)^{\mathrm{a}}$ & $50(23.6)$ & $24(25.0)$ & $25(22.7)$ \\
\hline \multirow[t]{4}{*}{ UTR-2 } & All & C & G & A & C & Ins & G & A & G & $55(28.6)$ & $76(35.8)$ & $\underline{40(41.7)^{\mathrm{a}}}$ & $34(30.9)$ \\
\hline & 01:01 & & & & & & & & & 38 (19.8) & $57(26.9)$ & $31(32.3)$ & $25(22.7)$ \\
\hline & $01: 05 \mathrm{~N}$ & & & & & & & & & $2(1.0)$ & $4(1.9)$ & $1(1.0)$ & $2(1.8)$ \\
\hline & 01:06 & & & & & & & & & $15(7.8)$ & $15(7.1)$ & 8 (8.3) & $7(6.4)$ \\
\hline UTR-3 & 01:04 & C & G & A & C & Del & G & A & C & $19(9.9)$ & $31(14.6)$ & $11(11.5)$ & $19(17.3)$ \\
\hline UTR-4 & 01:01 & G & $\mathbf{T}$ & $\mathbf{G}$ & C & Del & C & A & C & $16(8.3)$ & $24(11.3)$ & $11(11.5)$ & $12(10.9)$ \\
\hline UTR-5 & 01:03 & $\mathbf{T}$ & $\mathbf{T}$ & G & $\mathbf{T}$ & Ins & G & A & C & 17 (8.9) & $8(3.8)^{b}$ & $2(2.1)^{\circ}$ & $6(5.5)$ \\
\hline UTR-6 & 01:01 & C & $\mathbf{T}$ & $\mathbf{G}$ & C & Del & C & A & C & $13(6.8)$ & $14(6.6)$ & $4(4.2)$ & $9(8.2)$ \\
\hline UTR-7 & 01:01 & C & G & A & C & Ins & G & A & C & $18(9.4)$ & $8(3.8)$ & $\underline{3(3.1)^{d}}$ & $5(4.5)$ \\
\hline UTR-8 & 01:01 & C & G & $\mathbf{G}$ & C & Del & C & $\mathbf{G}$ & C & $3(1.6)$ & $1(0.5)$ & $1(1.0)$ & $0(0)$ \\
\hline
\end{tabular}

The polymorphic sites presented are in 5'URR at position $-725,-716,-201,-56$, and in $3^{\prime} U T R$, the 14 bp insertion/deletion, $+3,142,+3,187$, and $+3,196$. The most frequent human leukocyte antigen-G haplotypes considering the mRNA sequences, named according to Castelli et al. (33), are represented (UTR1-UTR8).

${ }^{a}$ For each subgroup of women tested, the first value represents the number of a given haplotype and the value between brackets indicates the frequency of this haplotype. All $P$ values to compare UTR frequencies from healthy women to UTR frequencies from SSc women are calculated by $\chi^{2}$ test. Corrections for multiple comparisons are done by Benjamini-Hochbergtest (PC).

${ }^{a} P=0.02, P_{C}=$ not significant

${ }^{b} P=0.034, P_{C}=$ not significant

${ }^{c} P=0.017, P C=$ not significant

${ }^{d} P=0.040, P C=$ not significant

Besides the role of HLA-G in pregnancy, several studies have indicated a wider immunoregulatory role of this molecule (60). In this context, the expression of HLA-G in inflammatory and rheumatologic diseases is a relatively recent research area. Our results open a new field of investigation for sHLA-G regulation in scleroderma. Finding the pathways explaining low production in women with SSc may also conduct to a better understanding for higher persistence of fetal Mc. HLA-G regulation is likely a key factor for FMc passage and maintenance. Animal models are now required as a proof of concept that maternal sHLA-G molecules play a role on higher traffic of fetal cells during pregnancy.

\section{ETHICS STATEMENT}

This study has received the approval from the French Ethical Committee Marseilles 2 and is registered at the INSERM (Biomedical Research Protocol number RBM-04-10). All participants signed written consent forms according to the Declaration of Helsinki (42).

\section{AUTHOR CONTRIBUTIONS}

JC, KK, CP, and NL conceived and designed the experiments. JC, KK, SK, DA, MH, and LH performed the experiments. JC,

\section{REFERENCES}

1. Allanore Y, Simms R, Distler O, Trojanowska M, Pope J, Denton CP, et al. Systemic sclerosis. Nature Reviews Disease Primers (2015) 1:15002.

2. Furst DE, Clements PJ, Graze P, Gale R, Roberts N. A syndrome resembling progressive systemic sclerosis after bone marrow transplantation. A model for scleroderma? Arthritis Rheum (1979) 22(8):904-10. doi:10.1002/art.1780220815
KK, EP, CP, and NL analyzed the data. DF-B, BG, JH, EH, and JR contributed to patient and control recruitments. JC, KK, CP, and NL wrote the paper.

\section{ACKNOWLEDGMENTS}

We would like to deeply thank Adja Magatte and Fu Ziheng (Institute of Mathematics, Marseille, France) who provided helpful advices for statistical analyses.

\section{FUNDING}

This work was supported by the Groupe Francophone de Recherche sur la Sclérodermie (GFRS), Association des Sclérodermiques de France (ASF). The funders had no role in study design, data collection and analysis, decision to publish, or preparation of the manuscript.

\section{SUPPLEMENTARY MATERIAL}

The Supplementary Material for this article can be found online at https:/www.frontiersin.org/articles/10.3389/fimmu.2018.01685/ full\#supplementary-material.
3. Silman A. Scleroderma. In:Hochberg MC, editor. Epidemiology of the Rheumatic Diseases. Oxford, United Kingdom: Oxford Press (1993). p. 192-219.

4. Nelson JL. Maternal-fetal immunology and autoimmune disease: is some autoimmune disease auto-alloimmune or allo-autoimmune? Arthritis Rheum (1996) 39(2):191-4. doi:10.1002/art.1780390203

5. Lambert NC. Autoimmune diseases. In: Draper NL, editor. Chimerism: A Clinical Guide. New York: Springer (2018). p. 153-79. 
6. Artlett CM, Smith JB, Jimenez SA. Identification of fetal DNA and cells in skin lesions from women with systemic sclerosis. N Engl J Med (1998) 338(17):1186-91. doi:10.1056/NEJM199804233381704

7. Scaletti C, Vultaggio A, Bonifacio S, Emmi L, Torricelli F, Maggi E, et al. Th2-oriented profile of male offspring $\mathrm{T}$ cells present in women with systemic sclerosis and reactive with maternal major histocompatibility complex antigens. Arthritis Rheum (2002) 46(2):445-50. doi:10.1002/art.10049

8. Burastero SE, Galbiati S, Vassallo A, Sabbadini MG, Bellone M, Marchionni L, et al. Cellular microchimerism as a lifelong physiologic status in parous women: an immunologic basis for its amplification in patients with systemic sclerosis. Arthritis Rheum (2003) 48(4):1109-16. doi:10.1002/art.10888

9. Nelson JL, Furst DE, Maloney S, Gooley T, Evans PC, Smith A, et al. Microchimerism and HLA-compatible relationships of pregnancy in scleroderma. Lancet (1998) 351(9102):559-62. doi:10.1016/S0140-6736(97)08357-8

10. Miyashita Y, Ono M, Ueki H, Kurasawa K. Y chromosome microchimerism in rheumatic autoimmune disease. Ann Rheum Dis (2000) 59(8):655-6. doi:10.1136/ard.59.8.654b

11. Ohtsuka T, Miyamoto Y, Yamakage A, Yamazaki S. Quantitative analysis of microchimerism in systemic sclerosis skin tissue. Arch Dermatol Res (2001) 293(8):387-91. doi:10.1007/s004030100245

12. Rak JM, Pagni PP, Tiev K, Allanore Y, Farge D, Harle JR, et al. Male microchimerism and HLA compatibility in French women with sclerodema: a different profile in limited and diffuse subset. Rheumatology (Oxford) (2009) 48(4):363-6. doi:10.1093/rheumatology/ken505

13. Lambert NC, Evans PC, Hashizumi TL, Maloney S, Gooley T, Furst DE, et al. Cutting edge: persistent fetal microchimerism in $\mathrm{T}$ lymphocytes is associated with HLA-DQA $1^{\star} 0501$ : implications in autoimmunity. J Immunol (2000) 164(11):5545-8. doi:10.4049/jimmunol.164.11.5545

14. Reed AM, McNallan K, Wettstein P, Vehe R, Ober C. Does HLA-dependent chimerism underlie the pathogenesis of juvenile dermatomyositis? J Immunol (2004) 172(8):5041-6. doi:10.4049/jimmunol.172.8.5041

15. Dahl M, Djurisic S, Hviid TV. The many faces of human leukocyte antigen-G: relevance to the fate of pregnancy. JImmunol Res (2014) 2014:591489. doi:10.1155/2014/591489

16. Ishitani A, Geraghty DE. Alternative splicing of HLA-G transcripts yields proteins with primary structures resembling both class I and class II antigens. Proc Natl Acad Sci U S A (1992) 89(9):3947-51. doi:10.1073/pnas.89.9.3947

17. Carosella ED, Moreau P, Le Maoult J, Le Discorde M, Dausset J, RouasFreiss N. HLA-G molecules: from maternal-fetal tolerance to tissue acceptance. Adv Immunol (2003) 81:199-252. doi:10.1016/S0065-2776(03)81006-4

18. Le Bouteiller P. HLA-G in human early pregnancy: control of uterine immune cell activation and likely vascular remodeling. Biomed J (2015) 38(1):32-8. doi:10.4103/2319-4170.131376

19. Alegre E, Diaz-Lagares A, Lemaoult J, Lopez-Moratalla N, Carosella ED, Gonzalez A. Maternal antigen presenting cells are a source of plasmatic HLA-G during pregnancy: longitudinal study during pregnancy. Hum Immunol (2007) 68(8):661-7. doi:10.1016/j.humimm.2007.04.007

20. Marozio L, Garofalo A, Berchialla P, Tavella AM, Salton L, Cavallo F, et al. Low expression of soluble human leukocyte antigen $\mathrm{G}$ in early gestation and subsequent placenta-mediated complications of pregnancy. J Obstet Gynaecol Res (2017) 43(9):1391-6. doi:10.1111/jog.13377

21. Kalotra V, Lall M, Verma IC, Kaur A, Kaur A. The HLA-G 14 bp insertion/ deletion polymorphism and its association with soluble HLA-G levels in women with recurrent miscarriages. HLA (2018) 91(3):167-74. doi:10.1111/ $\tan .13198$

22. Yie SM, Li LH, Li YM, Librach C. HLA-G protein concentrations in maternal serum and placental tissue are decreased in preeclampsia. Am J Obstet Gynecol (2004) 191(2):525-9. doi:10.1016/j.ajog.2004.01.033

23. Yie SM, Taylor RN, Librach C. Low plasma HLA-G protein concentrations in early gestation indicate the development of preeclampsia later in pregnancy. Am J Obstet Gynecol (2005) 193(1):204-8. doi:10.1016/j.ajog. 2004.11.062

24. Gammill HS, Aydelotte TM, Guthrie KA, Nkwopara EC, Nelson JL. Cellular fetal microchimerism in preeclampsia. Hypertension (2013) 62(6):1062-7. doi:10.1161/HYPERTENSIONAHA.113.01486

25. Vlkova B, Turna J, Celec P. Fetal DNA in maternal plasma in preeclamptic pregnancies. Hypertens Pregnancy (2015) 34(1):36-49. doi:10.3109/10641955. 2014.954722
26. Silman AJ, Black C. Increased incidence of spontaneous abortion and infertility in women with scleroderma before disease onset: a controlled study. Ann Rheum Dis (1988) 47(6):441-4. doi:10.1136/ard.47.6.441

27. Silman AJ, Roman E, Beral V, Brown A. Adverse reproductive outcomes in women who subsequently develop rheumatoid arthritis. Ann Rheum Dis (1988) 47(12):979-81. doi:10.1136/ard.47.12.979

28. van Wyk L, van der Marel J, Schuerwegh AJ, Schouffoer AA, Voskuyl AE, Huizinga TW, et al. Increased incidence of pregnancy complications in women who later develop scleroderma: a case control study. Arthritis Res Ther (2011) 13(6):R183. doi:10.1186/ar3510

29. Solier C, Aguerre-Girr M, Lenfant F, Campan A, Berrebi A, Rebmann V, et al. Secretion of pro-apoptotic intron 4-retaining soluble HLA-G1 by human villous trophoblast. Eur J Immunol (2002) 32(12):3576-86. doi:10.1002/ 1521-4141(200212)32:12<3576::AID-IMMU3576>3.0.CO;2-M

30. Rebmann V, van der Ven K, Passler M, Pfeiffer K, Krebs D, Grosse-Wilde H. Association of soluble HLA-G plasma levels with HLA-G alleles. Tissue Antigens (2001) 57(1):15-21. doi:10.1034/j.1399-0039.2001.057001015.x

31. Hviid TV, Hylenius S, Rorbye C, Nielsen LG. HLA-G allelic variants are associated with differences in the HLA-G mRNA isoform profile and HLA-G mRNA levels. Immunogenetics (2003) 55(2):63-79.

32. Ober C, Aldrich CL, Chervoneva I, Billstrand C, Rahimov F, Gray HL, et al. Variation in the HLA-G promoter region influences miscarriage rates. Am J Hum Genet (2003) 72(6):1425-35. doi:10.1086/375501

33. Castelli EC, Mendes-Junior CT, Deghaide NH, de Albuquerque RS, Muniz YC, Simoes RT, et al. The genetic structure of 3'untranslated region of the HLA-G gene: polymorphisms and haplotypes. Genes Immun (2010) 11(2):134-41. doi:10.1038/gene.2009.74

34. Larsen MH, Hylenius S, Andersen AM, Hviid TV. The 3'-untranslated region of the HLA-G gene in relation to pre-eclampsia: revisited. Tissue Antigens (2010) 75(3):253-61. doi:10.1111/j.1399-0039.2009.01435.x

35. Donadi EA, Castelli EC, Arnaiz-Villena A, Roger M, Rey D, Moreau P. Implications of the polymorphism of HLA-G on its function, regulation, evolution and disease association. Cell Mol Life Sci (2011) 68(3):369-95. doi:10.1007/s00018-010-0580-7

36. Jassem RM, Shani WS, Loisel DA, Sharief M, Billstrand C, Ober C. HLA-G polymorphisms and soluble HLA-G protein levels in women with recurrent pregnancy loss from Basrah province in Iraq. Hum Immunol (2012) 73(8):811-7. doi:10.1016/j.humimm.2012.05.009

37. Carlini F, Traore K, Cherouat N, Roubertoux P, Buhler S, Cortey M, et al. HLA-G UTR haplotype conservation in the Malian population: association with soluble HLA-G. PLoS One (2013) 8(12):e82517. doi:10.1371/journal. pone. 0082517

38. Hviid TV, Rizzo R, Melchiorri L, Stignani M, Baricordi OR. Polymorphism in the 5' upstream regulatory and 3' untranslated regions of the HLA-G gene in relation to soluble HLA-G and IL-10 expression. Hum Immunol (2006) 67(1-2):53-62. doi:10.1016/j.humimm.2005.12.003

39. Rizzo R, Bortolotti D, Fredj NB, Rotola A, Cura F, Castellazzi M, et al. Role of HLA-G $14 \mathrm{bp}$ deletion/insertion and $+3142 \mathrm{C}>\mathrm{G}$ polymorphisms in the production of sHLA-G molecules in relapsing-remitting multiple sclerosis. Hum Immunol (2012) 73(11):1140-6. doi:10.1016/j.humimm.2012.08.005

40. Svendsen SG, Hantash BM, Zhao L, Faber C, Bzorek M, Nissen MH, et al. The expression and functional activity of membrane-bound human leukocyte antigen-G1 are influenced by the 3 '-untranslated region. Hum Immunol (2013) 74(7):818-27. doi:10.1016/j.humimm.2013.03.003

41. LeRoy EC, Black C, Fleischmajer R, Jablonska S, Krieg T, Medsger TA Jr, et al. Scleroderma (systemic sclerosis): classification, subsets and pathogenesis. J Rheumatol (1988) 15(2):202-5.

42. Vollmann J, Winau R. Informed consent in human experimentation before the Nuremberg code. BMJ (1996) 313(7070):1445-9. doi:10.1136/ bmj.313.7070.1445

43. Rebmann V, Lemaoult J, Rouas-Freiss N, Carosella ED, Grosse-Wilde H. Report of the wet workshop for quantification of soluble HLA-G in Essen, 2004. Hum Immunol (2005) 66(8):853-63. doi:10.1016/j.humimm.2005. 05.003

44. Lambert NC, Erickson TD, Yan Z, Pang JM, Guthrie KA, Furst DE, et al. Quantification of maternal microchimerism by HLA-specific real-time polymerase chain reaction - studies of healthy women and women with scleroderma. Arthritis Rheum (2004) 50(3):906-14. doi:10.1002/art.20200 
45. Di Cristofaro J, El Moujally D, Agnel A, Mazieres S, Cortey M, Basire A, et al. HLA-G haplotype structure shows good conservation between different populations and good correlation with high, normal and low soluble HLA-G expression. Hum Immunol (2013) 74(2):203-6. doi:10.1016/j.humimm. 2012.10.027

46. Andersen MH, Fensterle J, Ugurel S, Reker S, Houben R, Guldberg P, et al. Immunogenicity of constitutively active V599EBRaf. Cancer Res (2004) 64(15):5456-60. doi:10.1158/0008-5472.CAN-04-0937

47. Di Cristofaro J, Reynaud-Gaubert M, Carlini F, Roubertoux P, Loundou A, Basire A, et al. HLA-G*01:04 approximately UTR3 recipient correlates with lower survival and higher frequency of chronic rejection after lung transplantation. Am J Transplant (2015) 15(9):2413-20. doi:10.1111/ajt.13305

48. Izbicki R, Fossaluza V, Hounie AG, Nakano EY, de Braganca Pereira CA. Testing allele homogeneity: the problem of nested hypotheses. BMC Genet (2012) 13:103. doi:10.1186/1471-2156-13-103

49. Benjamini Y, Drai D, Elmer G, Kafkafi N, Golani I. Controlling the false discovery rate in behavior genetics research. Behav Brain Res (2001) 125(1-2):279-84. doi:10.1016/S0166-4328(01)00297-2

50. Brenol CV, Veit TD, Chies JA, Xavier RM. The role of the HLA-G gene and molecule on the clinical expression of rheumatologic diseases. Rev Bras Reumatol (2012) 52(1):82-91. doi:10.1590/S0482-50042012000100009

51. Dahl M, Klitkou L, Christiansen OB, Djurisic S, Piosik ZM, Skovbo P, et al. Human leukocyte antigen (HLA)-G during pregnancy part II: associations between maternal and fetal HLA-G genotypes and soluble HLA-G. Hum Immunol (2015) 76(4):260-71. doi:10.1016/j.humimm.2015.01.015

52. Favoino E, Favia IE, Vettori S, Vicenti C, Prete M, Valentini G, et al. Clinical correlates of human leucocyte antigen (HLA)-G in systemic sclerosis. Clin Exp Immunol (2015) 181(1):100-9. doi:10.1111/cei.12633

53. Contini P, Negrini S, Murdaca G, Borro M, Puppo F. Evaluation of membrane-bound and soluble forms of HLA-G in systemic sclerosis. Clin Exp Immunol (2018) 193(2):152-9. doi:10.1111/cei.13134

54. Nilsson LL, Djurisic S, Andersen AM, Melbye M, Bjerre D, Ferrero-Miliani L, et al. Distribution of HLA-G extended haplotypes and one HLA-E polymorphism in a large-scale study of mother-child dyads with and without severe preeclampsia and eclampsia. HLA (2016) 88(4):172-86. doi:10.1111/ $\tan .12871$

55. He Y, Chen S, Huang H, Chen Q. Association between decreased plasma levels of soluble human leukocyte antigen-G and severe pre-eclampsia. J Perinat Med (2016) 44(3):283-90. doi:10.1515/jpm-2015-0062

56. Moreau P, Mouillot G, Rousseau P, Marcou C, Dausset J, Carosella ED. HLA-G gene repression is reversed by demethylation. Proc Natl Acad Sci US A (2003) 100(3):1191-6. doi:10.1073/pnas.0337539100

57. Tang Y, Liu H, Li H, Peng T, Gu W, Li X. Hypermethylation of the HLA-G promoter is associated with preeclampsia. Mol Hum Reprod (2015) 21(9): 736-44. doi:10.1093/molehr/gav037

58. Meyer D, Single RM, Mack SJ, Erlich HA, Thomson G. Signatures of demographic history and natural selection in the human major histocompatibility complex Loci. Genetics (2006) 173(4):2121-42. doi:10.1534/genetics.105. 052837

59. Nowak I, Malinowski A, Barcz E, Wilczynski JR, Wagner M, Majorczyk E, et al. Possible role of HLA-G, LILRB1 and KIR2DL4 gene polymorphisms in spontaneous miscarriage. Arch Immunol Ther Exp (Warsz) (2016) 64(6): 505-14. doi:10.1007/s00005-016-0389-7

60. Gregori S. Editorial: HLA-G-mediated immune tolerance: past and new outlooks. Front Immunol (2016) 7:653. doi:10.3389/fimmu.2016.00653

Conflict of Interest Statement: The authors declare that the research was con ducted in the absence of any commercial or financial relationships that could be construed as a potential conflict of interest.

Copyright (c) 2018 Di Cristofaro, Karlmark, Kanaan, Azzouz, El Haddad, Hubert, Farge-Bancel, Granel, Harlé, Hachulla, Pardoux, Roudier, Picard and Lambert. This is an open-access article distributed under the terms of the Creative Commons Attribution License (CC BY). The use, distribution or reproduction in other forums is permitted, provided the original author(s) and the copyright owner(s) are credited and that the original publication in this journal is cited, in accordance with accepted academic practice. No use, distribution or reproduction is permitted which does not comply with these terms. 